\title{
App Currículo, escola e mobilidade
}

\section{Simão Pedro P. Marinho ${ }^{1}$, Ricardo Marques Nicolau², Vanda Arantes Araújo3, Carla Fernanda Gonçalves ${ }^{4}$}

${ }^{1}$ Programa de Pós-Gradução em Educação - Pontifícia Universidade Católica de Minas Gerais (PUC MINAS) - 30.535-901 - Belo Horizonte - MG - Brasil

${ }^{2}$ Programa de Pós-Gradução em Educação - Pontifícia Universidade Católica de Minas Gerais (PUC MINAS) - 30.535-901 - Belo Horizonte - MG - Brazil

${ }^{3}$ Universidade do Estado de Minas Gerais - Faculdade de Políticas Públicas "Tancredo Neves" - 31130-150 - Belo Horizonte - MG - Brasil

${ }^{4}$ Sistema FIEMG - Federação das Indústrias do Estado de Minas Gerais - 32.371-540 Belo Horizonte - MG - Brasil

marinhosepucminas.br, ricardo.nicolaudsva.pucminas.br, vanda.araujo@uemg.br, cfgoncalves@fiemg.com.br

Abstract. This paper aims to provide a reflection, under the light of various practices and research, on curricula, understood as dynamic processes, in the integration of digital information and communication technologies in Brazilian schools. Three generations of curricula were identified, associated with times marked by projects or technological innovations, in a chronology of the introduction of the computer into our schools. From the identification of curricula $1 G, 2 G$ and $3 G$, it is proposed a fourth curriculum, the App Curriculum. This new curriculum, also identified as Curriculum 4G, is recognized as necessary in the context of the widespread use of smartphones and tablets, devices that allow new multiple space-time dimensions for teaching and learning.

Resumo. O presente trabalho objetiva oferecer uma reflexão, à luz de diversas práticas e pesquisas, sobre os currículos, entendidos como processos dinâmicos, na integração das tecnologias digitais de informação e comunicação na escola brasileira. Três gerações de currículo foram identificadas, associadas a tempos demarcados por projetos ou inovações tecnológicas, em uma cronologia da introdução do computador em nossas escolas. A partir da identificação dos currículos $1 G, 2 G$ e 3G, propõe-se um quarto currículo, o App Currículo. Esse novo currículo, também identificado como Currículo $4 G$, é reconhecido como necessário no contexto da disseminada utilização de smartphones e tablets, dispositivos que possibilitam novas múltiplas dimensões espaço-tempos para o ensino e a aprendizagem.

\section{Introdução}

As profundas mudanças que ocorrem no mundo nos últimos anos, especialmente em decorrência dos avanços tecnológicos, impõem a construção de novos sentidos para a realidade. Para melhor compreendê-la é preciso inventar novas metáforas, desconstruir 
mitos sobre a tecnologia, reinventar o significado de ensinar e aprender (Aires, 2009), enfim, percorrer novos caminhos.

Neste texto, pretendemos refletir, de forma breve, sobre a trajetória de introdução das tecnologias digitais de informação e comunicação (TDIC) na escola brasileira, a partir dos últimos anos da década de 1980 até os dias atuais, buscando relacionar com o que seriam os currículos escolares na sua integração/incorporação ao longo desse período.

A recuperação da história das TDIC em sua relação com a escola brasileira até praticamente o final da última década do século XX está em Moraes (1997). Após aquele período, a expansão do uso da Internet e a chegada de novos dispositivos (laptops educacionais, tablets, smartphones), com uma utilização bastante ampliada no âmbito da sociedade, acabam atingindo, de uma forma ou outra a escola. O projeto Um Computador por Aluno, UCA, é possivelmente a mais importante novidade quando se fala de TDIC na escola. Trazendo o uso 1:1, em ambiente de imersão, com acesso permanente, por WIFI, à Internet, promovendo a inovação pedagógica associada à novidade tecnológica, o Projeto UCA estabelece uma marca importante na história da informática na escola brasileira. A partir desse Projeto, o uso individual do dispositivo para a aprendizagem, a disponibilidade imediata da tecnologia, no contraponto ao laboratório de informática com a exigência do agendamento de horários para as aulas, e a utilização das interfaces da chamada Web 2.0 passam a ser assunto na rotina das escolas. E quando os smartphones chegam, trazidos pelos próprios alunos, evidentemente que novas perspectivas de incorporação curricular das TDIC se oferecem, para além da perturbação do ambiente de aprendizagem que muitas vezes eles promovem.

Se consideramos os diversos tipos de tecnologia disponíveis para uso na escola ao longo dos últimos trinta anos, podemos estabelecer o que consideraremos como sendo as gerações de currículos na escola que integra as TDIC. Currículo entendido, aqui, a partir da etimologia da palavra, como um caminho, percurso. Avançando conceitualmente, vamos entende-lo como processo e produto das relações sociais, que se modificam no tempo para atender às necessidades e ajustar-se aos contextos, que aparecem de forma dinâmica. Sabemos que a escola tem tempos diferentes, é feita por pessoas diferentes com histórias diferentes, o que exige que o currículo seja dinâmico "para não perder a razão de ser" (Marinho, 2006, p.17). Assim, o currículo não poderá ser definido a priori e se constrói em circunstâncias, trazidas pelas transformações sociais que influenciam o contexto da escola, tais como as TDIC.

\section{Currículo $1 \mathrm{G}$}

Nos anos 1980, tempo das primeiras ações para levar o computador para escola da hoje Educação Básica no Brasil, surgem projetos como EDUCOM e FORMAR, que tinham como objetivos implantar laboratórios de informática nas escolas e formar professores para utilizá-los e levar os alunos a fazê-lo, introduzindo, de alguma forma, o uso do computador no ambiente escolar. (Moraes, 1997).

Nesse período, os então chamados microcomputadores eram bastante limitados, estavam nas escolas mas não na casa das famílias dos alunos e nem mesmo nas mãos dos professores, o uso possível era bastante restrito, até mesmo no tempo das aulas, em geral com 50 minutos de duração, com uma frequência semanal baixa. Naquele primeiro momento, as ações envolviam ensinar os alunos a usar os computadores. Em algumas 
escolas, registrava-se uma - ainda que restrita - possibilidade de uso de software para ensinar conteúdos. Iniciativas que podemos dizer mais avançadas levavam os alunos a programarem os computadores, notadamente com a linguagem Logo. Essa nos parece a primeira geração de currículo para o uso das TDIC na escola brasileira; é o currículo $1 \mathrm{G}$, no contexto do laboratório, do ensino de informática, ao invés de se ensinar com ela, em um tempo-espaço de aprendizagem restrito. O tempo era o da aula, com as atividades, em geral desenvolvidas em duplas ou trios de alunos desconfortáveis em frente a um microcomputador, com suas telas pequenas e monocromáticas, acontecendo em um único espaço, que Marinho (1998) identificou como sendo uma "ilha da fantasia", bem diferente dos demais ambientes da escola. O currículo $1 \mathrm{G}$ era marcado, ainda, por uma unipolaridade no que tange aos espaços de aprendizagem das/com as TDIC, representada pelo laboratório, sem qualquer conexão com o mundo exterior.

\section{Currículo 2G}

Os anos 1990 são marcados, no seu início, pela chegada dos kits multimídia, pelos monitores com profusão de cores. Nos meados daquela década, a internet chega ao Brasil e se torna disponível até para as escolas. A conexão do laboratório da escola com os espaços virtuais da internet se concretiza com o PROINFO, em 1997. Estabeleceram-se, assim, "janelas virtuais", através das quais o aluno passa a "ver o mundo" para além das paredes da escola. O acesso à World Wide Web, ainda que naquilo que hoje conhecemos como Web 1.0, onde apenas a leitura do que se oferece na imensa rede é possível. Tudo isso torna possível o acesso a enciclopédias em CD-ROM virtuais e a sites como fonte de consulta pelos alunos, na realização das chamadas "pesquisas escolares". É possível o uso de correio eletrônico, estudantes e professores começam a ter seus endereços no ciberespaço, newgroups. Novas tecnologias trazem novas oportunidades, e o currículo das/com as TDIC chega a sua segunda geração; é o currículo $2 \mathrm{G}$, associado a um segundo momento das TDIC no ambiente escolar. E, como é natural, a convivência de currículos pode ser identificada. Currículos $1 \mathrm{G}$ e $2 \mathrm{G}$ coexistem nas escolas.

Nesse período, ao menos para alguns - aqueles que possuíam computador em casa, com acesso à internet - , cria-se um outro polo de aprendizagem com as TDIC, a casa dos alunos. Atividades no polo "escola" persistem, ainda em laboratórios de informática, em tempos formatados, porque os das aulas. O currículo $2 \mathrm{G}$ se realiza, ainda que não para todos, em uma bipolaridade de espaços de aprendizagem. Ou seja, dois espaços-tempos de aprendizagem se configuraram, um é o antigo laboratório, com máquinas mais modernas agora conectadas à Internet, ainda que com um certo predomínio do ensino da informática, com computadores presos às paredes pelos cabos de rede. O outro é o domicílio, em situação semelhante no que tange aos equipamentos.

Ainda que avanços tecnológicos tenham ocorrido, as mudanças nas práticas pedagógicas não foram muito significativas, mesmo com a abertura de "janelas virtuais", uma metáfora para o acesso à internet, que permite que da escola se veja o mundo, através de web pages.

Um outro elemento importante surge mais para o final da década de 1990, com o uso de projetores multimídia ao qual se acopla um computador (ainda o desktop) que traz apresentações geradas com o PowerPoint. É o computador apoiando o ensino, o computador nas mãos apenas dos professores, numa prática que se expandiu e, em muitas 
escolas, torna-se hegemônica quando se trata de uso das TDIC com finalidade educacional.

\section{Currículo 3G}

No início da presente década algo absolutamente inovador acontece: o laptop educacional, uma tecnologia móvel, sem fio, trazida para a escola pelo Projeto Um Computador por Aluno, UCA, implantado pelo Governo Federal em 2010.

A chegada dos laptops na escola representa a possibilidade da mobilidade, agora os alunos têm máquinas que não se mantêm presas a paredes. Rompe-se, de alguma forma, com o modelo dos laboratórios de informática, pois agora o dispositivo está disponível para uso individual, no modelo 1:1, quando necessário. Professores não mais precisam agendar horários para que seus alunos utilizem computadores, eles estão ali, nas salas de aula, disponíveis, como cadernos e livros, para quando necessário. E com acesso permanente à internet.

Temos, assim, um novo cenário, com a possibilidade de uso individual do computador como um elemento a se integrar nas práticas educativas. Os limites (físicos) da sala de aula podem ser rompidos. Os outros espaços da escola, e até mesmo do seu entorno, se transformam em espaços para aprendizagem com as TDIC. E ainda uma outra significativa mudança ocorre.

O Projeto UCA potencializa a bipolaridade dos espaços de aprendizagem com as TDIC, pois os alunos podem levar os laptops educacionais para casa. Em alguns casos há, nos domicílios, uma limitação no acesso à internet. Em nem todos os domicílios há o acesso WiFi à internet, nem todas as casas dos alunos estão próximas a Access Points (AP) públicos. Na proposta do Projeto UCA, o uso das interfaces da chamada Web 2.0, a read-and-write Web imaginada por Tim Bernes Lee, é estimulado. Os alunos, integrando uma contemporânea Sociedade da Autoria (Marinho, 2009), agora podem se expressar na internet, levando as produções da aprendizagem para audiências autênticas.

Expandem-se os espaços educativos, ampliam-se os tempos para a aprendizagem com as TDIC, mas ainda em uma configuração bipolarizada; na escola, dentro do raio de alcance dos pontos de acesso WIFI, e no domicílio, do aluno e do professor, onde também começa a se ampliar a oferta de acesso à Internet. Nesse sentido, evoluem as "janelas virtuais" que agora podem ser abertas na escola ou na casa do aluno e do professor. É o currículo 3G, que além de "janelas" permite a realidade de "portas digitais", outra metáfora, através das quais a escola adentra no ciberespaço.

A ampliação das "janelas virtuais" acompanhou a introdução do ensino das tecnologias, ou o ensino com as tecnologias, desde a segunda metade da última década do século XX, sem, contudo, criar uma cultura digital (Buckingham, 2010), que permitisse a incorporação efetiva as TDIC ao currículo escolar. Surge, no momento do Projeto UCA, o Web Currículo (Almeida, 2011), em interessante exercício de proposição de um novo currículo para práticas com as TDIC.

Apesar de ser um conceito ainda em construção, o Web Currículo tem como pressuposto básico a integração das TDIC ao currículo de tal forma que a tecnologia se torne invisível, enquanto a aprendizagem torna-se visível. (Sanches, 1999). Assim, o Web 
Currículo, cujos elementos essenciais de constituição são o professor, o aluno, as TDIC, a cultura (digital), a proposta curricular e a prática pedagógica, pode ser concebido como:

\begin{abstract}
a relação que envolve distintas linguagens e sistemas de signos mobilizados na prática social midiatizada pelas TDIC, e configurados de acordo com as propriedades e funcionalidades intrínsecas das tecnologias e mídias digitais, que suportam e estruturam os modos de produção do currículo, sendo este produtor de transformações e reconfigurações das TDIC. Deste modo, as TDIC e o currículo, constituídos como unidades distintas, se determinam, formando uma totalidade e produzindo transformações recíprocas. (Almeida e Valente, 2012, p. 54)
\end{abstract}

A velocidade do avanço das TDIC é enorme e, sem que o currículo $3 \mathrm{G}$, que vemos em perfeita identidade com o Web Currículo, tenha se implantado de forma definitiva, a necessidade de um novo olhar sobre a tecnologia nos ambientes educativos surge com a entrada dos vários "artefatos tecnológicos" trazidos pelos alunos (celulares, tablets, etc.), para a sala de aula, em número cada vez maior e deve nos levar a pensar em um novo currículo, o currículo $4 \mathrm{G}$.

\title{
5. Currículo 4G
}

Recentes pesquisas mostram, inclusive no Brasil, uma crescente popularização do acesso à internet através de dispositivos móveis, como smartphones e tablets.

Para a pesquisa "TIC-Domicílios", realizada pelo Centro de Estudos sobre as Tecnologias da Informação e da Comunicação (CETIC.br) (Comitê Gestor da Internet no Brasil, 2014a), foram entrevistados 16.887 pessoas em 350 municípios brasileiros a fim de investigar de que maneira se dá a utilização do celular. Seus resultados revelam que mais da metade deles (55\%) afirma ser capaz de fotografar com a câmera do celular, assim como ouvir música (54\%). Uma em cada três pessoas conseguem assistir vídeos, um número ainda maior afirma conseguir jogar $(36 \%)$ e quase um terço deles declaram ter acesso às redes sociais (30\%). Praticamente um em cada quatro brasileiros (23\%) conseguem ter acesso a páginas ou sites e buscar aplicativos para uso em seus celulares.

Uma leitura dos dados da pesquisa nos permite afirmar que uma parcela considerável de indivíduos no Brasil declara ser capaz de utilizar um grande número de funcionalidades que os smartphones oferecem. Não seria este um sinal indicativo da possibilidade de se integrar tal tecnologia ao currículo da escola, de modo que estas práticas de interação e construção de conhecimento se concretizem? Seria essa uma demanda radical demais para professores e alunos? Talvez ela não seja tão complicada quanto parece. O estudo "TIC-Educação", também realizado pelo CETIC.br (2014b), revelou um aumento significativo no número de professores que utilizam o celular para o acesso à internet. Em 2010, poucos professores (6\%) faziam o acesso à rede com smartphones; três anos depois este número já era seis vezes maior (36\%).

O comportamento da população em geral, conforme a TIC-Domicílios 2013, é bastante similar ao dos educadores. Em 2010 a taxa de indivíduos que utilizava celulares para acesso à Internet era muito baixa (4\%); em 2013 este número já foi quase oito vezes maior $(31 \%)$.

Estes dados são importantes, pois revelam um número crescente de cidadãos, entre os quais, certamente, professores e alunos, que estão se apropriando do que a tecnologia móvel, assentada na telefonia $3 \mathrm{G}$ ou $4 \mathrm{G}$ oferece. Dispositivos como 
smartphones e tablets são utilizados por todo o tempo, levados por toda parte, quase que constituindo peça do vestuário.

Exatamente em função da mobilidade levada ao extremo, se forem utilizados no contexto escolar, permitirão que o currículo se expanda na escola, e para fora dela, através de "janelas virtuais móveis". Por meio dessas janelas metafóricas se ampliará a percepção de espaços-tempos dos processos de ensino e aprendizagem, trazendo a multipolaridade que suplanta a bipolaridade antes alcançada. A qualquer momento, em qualquer lugar, pode-se abrir uma "janela" para ver o mundo, uma "porta" para entrar no mundo, criando oportunidades de aprender e de mostrar o que se aprendeu.

Torna-se cada vez mais comum o compartilhamento de registros do cotidiano em vídeologs, ou em fotologs, capturados pela câmera de um smartphone. É frequente observar alguém ouvindo uma web radio ou um podcast. E além da linguagem visual, ou do áudio, a escrita também faz parte do cotidiano de quem troca mensagens por aplicações como Whatsapp, faz comentários em blogs, troca e-mails, curtidas no Facebook, contribui em wikis, além de utilizarem apps que estão disponíveis em um número quase ilimitado para qualquer smartphone, tenha sistema iOS ou Android.

A popularização dos apps se deve pela facilidade de instalação quase instantânea no smartphone ou no tablet, pelo baixo custo - quando existe - e pela versatilidade de produção e manutenção. Extremamente interativos, dispensam formação para o uso; são utilizados imediatamente, sem que alguém precise dizer como fazer. O conhecimento pode se constituir agora de forma colaborativa, também em outros tempos-espaços.

Estas mesmas formas de expressão e comunicação poderão ser incorporadas ao currículo, tanto para investigar, quanto para construir o conhecimento. E, no que começou a ser feito na escola com o Projeto UCA, para produzir e mostrar saberes para além da sala de aula, além da escola, para pessoas que não só mais o professor e os colegas, no compartilhamento de experiências reais, autênticas, integradas a uma cultura digital.

Marinho (2009) assevera que indivíduos imersos em uma cultura digital, possível pela Web 2.0, deixam de ser apenas coletores de informações e vão bem além. São sujeitos responsáveis por colaborar na criação de grandes repositórios de informações, semeando e contribuindo para que uma riqueza cognitiva se estabeleça e se expanda em um espaço cujo acesso é amplo, e em tese, possível a todos.

Desse modo, se até aqui havia "janelas para ver o mundo", com a autoria e (co)autoria, em um contexto em que existem conectividade e mobilidade plenas, criamse agora "portas virtuais" através das quais a escola pode se lançar para o mundo, para se integrar a ele. Através destas "portas" pode-se ir além de "ver" o mundo; a escola agora pode penetrar nele, como também permitir que o mundo entre nela. Em suma, de meros alunos receptores de informações, temos novos agentes que passam a produzir e partilhar conteúdos, saberes, construindo um conjunto de contatos, recursos, ferramentas e artefatos dinâmicos e mutáveis, ressignificando o currículo.

A convergência que se estabeleceu em torno de smartphones e tablets permite que sejam rompidas as barreiras de espaço-tempo que a ideologia do currículo como prescrição (Goodson, 2007) impunha à escola. Quando integrado às tecnologias que já estão sob o domínio daqueles que as carregam consigo todo o tempo, o currículo adquire múltipla mobilidade, juntamente com a multipolaridade. O que se revela pela 
possibilidade de se movimentar por múltiplos espaços e tempos distintos, uma vez que o currículo é permeável às colaborações aluno-professor, aluno-aluno.

No entanto, não se propõe um abandono completo do currículo formal que vem sendo adotado pela escola a fim de valorizar experiências fragmentadas. O que se pretende é chamar a atenção para as novas possibilidades que as tecnologias móveis oferecem, naquilo que chamamos de currículo 4G, e que podem conferir sentido ao saber que se constrói, na medida em que o professor as identifique e as articule com o currículo formal. Através dessa dinâmica, o currículo atinge sua significação enquanto "caminho", uma nova metodologia que considera a experiência cultural do aluno como elemento constitutivo do conhecimento que elabora. (Almeida e Valente, 2012).

É este um currículo que se atualiza continuamente acompanhando as mudanças sócio-históricas e culturais porque está interagindo com elas, sem que com isso perca sua orientação pedagógica, que permite a ação/intervenção do professor, que também autora na rede, destaca contextos, propõe reflexões críticas e atividades.

O currículo permanece, também, aberto às contribuições e demandas dos alunos, não mais restritas aos limites dos livros didáticos, ou do conteúdo, cujo acesso fica restrito a conexões realizadas no domicílio ou na escola. O currículo $4 \mathrm{G}$ se move, é dinâmico, acontecendo em qualquer instante da vida de alunos e professores, em qualquer lugar, a qualquer tempo, fazendo-se o uso de "portas e janelas móveis" através das quais alunos e professores veem o mundo e para ele apresentam a escola, estabelecendo um fluxo integrador, onde interagem a cultura, o aluno, o currículo, o conteúdo e o professor, estabelecendo uma aprendizagem contextualizada, com todos (co)autorando $\mathrm{e}$ (co)aprendendo.

É dessa forma que a conectividade e mobilidade plenas corroboram para que a escola se integre à sociedade, na medida em que "portas e janelas móveis" podem ser abertas em qualquer lugar, em qualquer momento no qual alguém se conectar. Através dessas portas estabelecem-se fluxos de saberes que caracterizam o currículo 4G, aqui denominado como App Currículo. Esse currículo avança em relação ao Web Currículo, até porque o toma como referência, tira alunos e professores da bipolaridade dos espaços de aprendizagem. O Currículo 4G caracteriza-se pela multipolaridade, pela expansão de espaços-tempos de aprendizagem, pelo uso dos App, pelas ações de autoria e (co)autoria e pelo compartilhamento de saberes. O Currículo 4G, ou App Currículo, traz consigo marcas do Web Currículo, mas se coloca como novos caminho e processo, em um novo tempo, até porque as tecnologias já são outras.

\section{Demandas e possibilidades}

A abertura de novos espaços de leitura e escrita, novos ambientes antes nem imaginados, surge e muitas vezes se impõe como uma necessidade inquestionável. Os app são uma interessante alternativa ao modelo de aplicações complexas que nas últimas três décadas somente podiam ser construídas por empresas, para uso quase exclusivo nos computadores.

Entretanto, é possível ir além de criar conteúdos utilizando ferramentas complexas. É possível ao professor criar os próprios aplicativos, pois existem ferramentas de utilização muito simples para isso. Os app criados pelos professores ganham especial 
destaque por serem construídos "sob medida" para um uso "just-in-time", no contexto próprio onde se dá a ação educativa do professor ${ }^{1}$. Em função de sua simplicidade estrutural, eles podem ser criados por professores e alunos, compartilhados na Internet, para que outros possam instalá-los em seus dispositivos. Atualmente, há inúmeras "fábricas de aplicativos" que orientam e facilitam a criação de App, algumas delas, gratuitamente.

De posse de um smartphone o aluno pode pesquisar em dicionários através de app de editoras produtoras de conteúdos digitais disponíveis. Há também os QRcode que, lidos através de app nos smartphones, permitem acesso imediato a fontes diversas online. Essa funcionalidade incorpora uma camada digital de informação aos livros, integrando a experiência tangível material com a experiência digital intangível. A proposta é tornar a leitura mais interativa. Algumas escolas também utilizam esse recurso, e afixam em seus murais vários QRcode como forma de apresentar conteúdos, informações e dicas de maneira mais integrada e divertida.

A rede social Foursquare, disponível para todo tipo de smartphone, pode ser aproveitada nas disciplinas de Geografia e História, como ferramenta de localização e mapas on-line, e também como palco fértil de reflexão, debate, dúvidas, atualizações sobre os conteúdos estudados, links visitados e temas da atualidade tão cobrados nas provas, exames e concursos.

Entretanto, não se trata apenas de baixar e compartilhar materiais, livros, conteúdos, vídeos ou fotos, mas de investigar, pesquisar, reconhecer e usá-los gerando novas relações, novos signos, novos sistemas conceituais, porque aprender não é reproduzir, mas redescobrir. Nesse sentido, não significa que o professor tenha que usar em suas aulas tudo o que aparece como novidade, mas sim utilizar o que possa contribuir de fato para a aprendizagem. Tampouco ele terá que abandonar as aplicações que comumente utiliza no desktop, pois determinadas tarefas serão melhor executadas nele, tais como a edição de vídeo, áudio e imagens, entre outras. As novas tecnologias trazidas para escola pelo menos por enquanto não significam o fim do laboratório de informática. Novos recursos podem solucionar dificuldades, despertar curiosidade e sustentar o processo de desenvolvimento de novas atividades; mas não obrigam que os recursos anteriores sejam eliminados sem ganhos de qualidade.

Por isso, é importante vencer as distâncias entre aquilo que se pretende e o mundo real. Muitas são as demandas a serem enfrentadas para que se consolide um currículo com múltiplas mobilidades: a alta rotatividade dos professores, principalmente nas escolas das redes públicas; a infraestrutura para acesso à internet, a qualidade da telefonia móvel e da internet banda larga que ainda deixam muito a desejar na realidade brasileira, o número excessivo de alunos em sala de aula, a sobrecarga de trabalho docente, o estresse cognitivo, a invasão da privacidade e o imbricar entre a vida pessoal e profissional (Almeida; Alves; Lemos, 2014). Mas, um aspecto é importante: quando a tecnologia a ser usada na escola é o smartphone, trazida pelo aluno, dispensa a escola de investir na sua aquisição e manutenção, situação diferente daquela dos laboratórios de informática e até mesmo dos laptops educacionais, livra-a em parte de problemas.

\footnotetext{
1 O professor Simão Pedro P. Marinho desenvolveu um app para uso em disciplina no Programa de Pós-graduação em Educação da PUC Minas, através do qual mantém os alunos informados sobre a agenda, recomenda vídeos, permite acesso imediato ao Twitter da disciplina.
} 
Tal cenário está na pauta das discussões da atualidade, visto que a tecnologia vem ocupando novos espaços-tempos na medida em que se amplia a mobilidade. Contudo, não se pode esquecer que uma significativa carga de stress ocorre, não pela inexistência da tecnologia, mas pela deficiência da infraestrutura disponível, bem como de fatores sociais e da condição de trabalho no mundo da escola.

Percebe-se, ainda, um receio de professores para utilizar as TDIC na sala de aula com objetivo de criar novas formas de ensinar. Um significativo percentual dele se posiciona até mesmo contra a utilização da TDIC em sala de aula, ou simplesmente não visualiza seu potencial pedagógico, muito embora possuam o conhecimento necessário para manipulá-las, já que as utilizam, com intimidade, em seu cotidiano. Essa posição na defensiva de alguns professores é, não raro, um fugir à necessidade de mudar práticas pedagógicas, é uma forma de resistir a abandonar a zona de conforto pedagógico em que estão. Portanto, a necessidade de o professor, mesmo em meio a esta situação, buscar perseguir novos caminhos para aproveitar em sua prática pedagógica as ferramentas que ele e seus alunos já utilizam nos parece imperiosa. Tecnologicamente podem estar preparados, mas alguns ainda carecerão da preparação pedagógica.

O papel da educação será sempre o de "fornecer condições para a criação de ambientes significativos que favoreçam, efetivamente, o conhecimento e o desenvolvimento de novas habilidades cognitivas". (Costa, Oliveira, 2004, p. 20).

Sabe-se que não existem fórmulas prontas no processo de ensino e aprendizagem, nada que a priori assegure seu sucesso. Mas, não há outra saída que não seja a superação. Assim, para que a educação brasileira possa acompanhar e se apropriar do Currículo 4G, ou App Currículo, a fim de favorecer o processo de ensino e aprendizagem, é preciso que todos os envolvidos no processo educacional reflitam sobre a importância desse deslocamento de espaço-tempo permitido pelos smartphones ${ }^{2}$ e entendam a relevância da flexibilização que a educação tanto requer e precisa. Talvez, desta forma sejamos capazes de continuar a inventar novas metáforas, desconstruir mitos sobre a tecnologia, reinventar o significado de ensinar e aprender e seguir nosso caminho na direção do futuro.

E, como nos lembra Marinho (2014) ao citar Edgard Morin, "no começo a mudança é apenas um desvio".

\section{Referências}

Aires, L. (2009). Tecnologia educativa: la formación del profesorado en la era de internet. Prisma.com, n.9, 2010. Recuperado em 11, setembro, 2014 de http://revistas.ua.pt/index.php/prismacom/article/view/701/pdf.

Almeida, M. E. B., Silva, M.G. M. (2011). Currículo, tecnologia e cultura digital: espaços e tempos de web currículo. Revista e-curriculum, v. 7, n.1, abr. 2011 ISSN: 1809-3876. Recuperado em 05, setembro, 2014, de http://revistas.pucsp.br/index.php/curriculum/article/viewFile/5676/4002.

Almeida, M. E. B.,Valente, J. A. (2012). Integração currículo e tecnologias e a produção de narrativas digitais. Currículo sem Fronteiras, v. 12, n. 3, p. 57-82,

\footnotetext{
2 Enfatiza-se muito aqui o smartphone, mas um papel semelhante caberá aos tablets, desde que providos de chips de telefonia móvel, não ficando na dependência do acesso WiFI à internet, o que restringe amobilidade.
} 
Set/Dez 2012. Recuperado em 05, setembro, 2014, de http://www.curriculosemfronteiras.org/vol12iss3articles/almeida-valente.pdf.

Almeida, M. E. B., Alves, R. M., Lemos, S. D. V. (Org.). (2014). Web Currículo: aprendizagem, pesquisa e conhecimento com o uso de tecnologias digitais. Rio de Janeiro: Letra Capital. Recuperado em 06, setembro, 2014, de http://www.letracapital.com.br/joomla.

Buckingham, D. (2010). Cultura digital, educação midiática e o lugar da escolarização. Educação \& Realidade. Porto Alegre, v. 35, n. 3, p. 37-58, set./dez., 2010. Recuperado em 08, setembro, 2014, de http://www.ufrgs.br/edu_realidade.

Comitê Gestor da Internet no Brasil. (2014a). Pesquisa TIC Domicílios 2013: pesquisa sobre o uso das tecnologias de informação e da comunicação no Brasil. São Paulo: Comitê Gestor da Internet no Brasil, 2014. Recuperado em 05, setembro, 2014, de http://cetic.br/media/analises/tic-domicilios-2013.pdf.

Comitê Gestor da Internet no Brasil. (2014b). Pesquisa TIC Educação 2013: Pesquisa sobre o uso das tecnologias de informação e da comunicação no Brasil. São Paulo: Comitê Gestor da Internet no Brasil, 2014. Recuperado em 05, setembro, 2014, de http://cetic.br/media/analises/tic-educacao-apresentacao-2013.pdf.

Costa, J. W., Oliveira, M. A. (2004). Novas linguagens e novas tecnologias. Educação e Sociedade. Petrópolis (Rio de Janeiro): Vozes.

Goodson, I.(2007). Currículo, narrativa e o futuro. Tradução Eurize Caldas Pessanha e Marta Banducci Rahe. Revista Brasileira de Educação, v. 12, n. 3,5 maio/ago. 2007. Recuperado em 06, setembro, 2014, de http://www.scielo.br/pdf/rbedu/ v12n35/a05v1235.pdf.

Marinho, S. P. P. (2014). A educação na pós-modernidade. Aula da disciplina Educação, Sociedade e Tecnologia. Programa de Pós-Graduação em Educação. PUC MG, 2014. [slide].

Marinho, S. P. P. (2009). Oportunidades e possibilidades para a inserção de interfaces da Web. 2.0 no currículo da escola em tempos de convergências de mídia. Recuperado em 12, setembro, 2014, de httpwww.pucsp.br/ecurriculum.

Marinho, S. P. P. (2006). Novas tecnologias e velhos currículos; já é hora de sincronizar. Recuperado em 08, setembro, 2014, de http://www.pucsp.br /ecurriculum.

Marinho, S. P. P. (1998). Educação na era da informação: os desafios na incorporação do computador na escola. Recuperado em 03, setembro, 2014, de http:// https://www.academia.edu/250560/Educacao_Na_Era_Da_Informacao_Os_Desafios _Na_Incorporacao_Do_Computador

Moraes, M. C.(1997). Informática educativa no Brasil: uma história vivida, algumas lições aprendidas. Revista Brasileira de Informática na Educação, v. 1, n. 1, abr. 1997. Recuperado em 04, setembro, 2014, de http://brie.org/pub/index.php/rbie/article/viewFile/2320/2082.

Sánchez, J. (1999). Aprendizaje Visible, Tecnología Invisible. Santiago, 1999. Recuperado em 05, setembro, 2014, de http://users.dcc.uchile.cl/ jsanchez/Pages/ papers/avisible.pdf. 